\title{
Strength Properties of Abdominal Wall in Intraperitoneal and Retromuscular Repair Using Lightweight and Ultra-Lightweight Synthetic and Titanium-Containing Endoprostheses (Experimental Study)
}

\author{
DOI: $10.17691 / \mathrm{stm} 2016.8 .3 .03$
}

Received June 24, 2015

V.V. Parshikov, MD, DSc, Professor, Department of Hospital Surgery named after B.A. Korolyov';

A.A. Kazantsev, Researcher, Research and Methodology Department2;

A.A. Mironov, PhD, Associate Professor, Department of Neurotechnology, Institute of Biology and Biomedicine ${ }^{3}$; Senior Researcher, Experimental Modeling Unit, Central Scientific Research Laboratory';

V.A. Zavaruev, DSc, Professor, Department of Product Design and Styling4;

A.N. Chernikov, PhD, Professor, Department of Spinning

O.F. Belayev, DSc, Professor, Department of Product Design and Styling4;

A.I. Alyokhin, MD, DSc, Deputy Chief Doctor on Scientific Work; Head of Research and Educational Center ${ }^{2}$

${ }^{1}$ Nizhny Novgorod State Medical Academy, 10/1 Minin and Pozharsky Square, Nizhny Novgorod, 603005,

Russian Federation;

${ }^{2}$ Central Clinical Hospital of the Russian Academy of Sciences, 10 Fotiyevoy St., Moscow, 119333, Russian Federation;

${ }^{3}$ Lobachevsky State University of Nizhni Novgorod, 23 Prospekt Gagarina, Nizhny Novgorod, 603950,

Russian Federation;

${ }^{4}$ Moscow State Design and Technology University, 33, Bld. 1 Sadovnichevskaya St., Moscow, 117997,

Russian Federation

The application of ultra-lightweight materials for abdominal wall hernia repair has not been controlled so far, and the capabilities of synthetic and titanium-containing endoprostheses, as well as the peculiarities and possible differences in connective tissue development in an implantation area are not adequately investigated.

The aim of the investigation was to study in experiment strength properties of connective tissue formation in the area of synthetic and titanium-containing endoprostheses implanted during abdominal wall prosthetic repair.

Materials and Methods. Abdominal wall prosthetic repair was simulated in rabbits. The first series animals underwent retromuscular (sublay retromuscular, SRM) implantation, the second series - intraperitoneal (intraperitoneal onlay mesh, IPOM). We used the model including implantation of two meshes situated in close proximity to each other. Group 1 animals were implanted synthetic lightweight polypropylene meshes (90 $\mu \mathrm{m}$ fiber), group 2 - ultra-lightweight titanium-containing meshes (made of lightweight polypropylene titanium-coated, $65 \mu \mathrm{m}$ fiber), group 3 were implanted titanium (65 $\mu \mathrm{m}$ fiber) endoprostheses. 30 and 60 days later the animals were sacrificed, their abdominal wall strength being studied in the contact area of meshes. Intact abdominal wall areas were control.

Results. Connective tissue strength in group 2 was higher $(13.12 \mathrm{~N} / \mathrm{cm})$ compared to group $1(9.2 \mathrm{~N} / \mathrm{cm})$ in both series, $p=0.001$. In group 3 the parameter under study was maximal $(15.89 \mathrm{~N} / \mathrm{cm})$, which differed significantly from that in group $1(p=0.0000)$ and $2(p=0.002)$. The comparison showed connective tissue strength after SRM to be higher $(13.32 \mathrm{~N} / \mathrm{cm})$ than after IPOM $(12.88 \mathrm{~N} / \mathrm{cm}) ; p=0.976$. The parameter was significantly higher on day 60 of the experiment $(13.9 \mathrm{~N} / \mathrm{cm})$ compared to that on day $30(12.4 \mathrm{~N} / \mathrm{cm}) ; p=0.008$. On day 30 the abdominal wall strength along the implantation perimeter was significantly lower $(12.4 \mathrm{~N} / \mathrm{cm})$ compared to inrtact areas $(14.84 \mathrm{~N} / \mathrm{cm})$; $p=0.0004$. No significant differences in strength between the areas under study and intact areas $(13.9 \mathrm{~N} / \mathrm{cm})$ were found by the $60^{\text {th }}$ postoperative day; $p=0.08$.

Conclusion. The application of lightweight and ultra-lightweight synthetic and titanium-containing endoprostheses for abdominal wall repair is accompanied by the formation of connective tissue of adequate strength. The abdominal wall along the implantation perimeter has satisfactory parameters of tensile strength comparable with intact abdominal wall strength, and by day 60 after surgery the parameters are

For contacts: Vladimir V. Parshikov, e-mail: pv1610@mail.ru 
no different from an intact wall. Lightweight and ultra-lightweight meshes are safe to use in clinical settings in case of adequate abdominal wall reconstruction. Strength characteristic in experiment was determined for surgically operated (newly formed) abdominal wall, not only for mesh or connective tissue capsule. It is of great importance for hernia prognosis and recurrence prevention.

Key words: prosthetic repair; mesh; hernia; synthetic endoprostheses; titanium-containing endoprostheses; connective tissue strength.

Patients with abdominal wall hernias constitute a large part of patient population in general surgical inpatient departments [1-5]. The selection of mesh implant for abdominal wall repair presents a challenging problem, which is unsolved so far $[4,6]$. The improvement in techniques, and development of new materials and surgical methods have resulted in a great variety of both: endoprostheses themselves, and also the variations of surgical approaches. Despite the background of experience, and extensive publications of study findings, the decision making in certain clinical settings, to a large extent, is prerogative power of an operating surgeon. For ease of practical application, modern classifications have been advanced, which describe in detail the characteristics of various meshes [7-9]. Recently, the advantages and disadvantages of lightweight and ultra-lightweight materials are being actively discussed compared to standard and heavy endoprostheses. There are reports demonstrating a reduced number of early and late postoperative complications without recurrence rate increase [10], and representing the advantages of lightweight meshes related to the life quality of operated patients [11]. Other researchers show no significant differences in different meshes when studying long-term results [12]. Some famous surgeons show that care is required when using lightweight materials, since their application is associated with relatively high recurrence rate [13]. Till the present time no consensus has been reached yet. Most hernia recurrences are well known to develop along a mesh edge. Peak of recurrences is found in the middle and at the end of the first postoperative year [14]. The fact is that an endoprosthesis is always stronger than an abdominal wall itself, the latter in hernia-carriers and operated patients having major morphological changes [15, 16]. It may happen that strength characteristics of connective tissue, which develops in the implantation area, are of certain significance for hernia recurrence risk. However, the peculiarities of morphological structure and biomechanics of an abdominal wall in patients with hernias and in patients with endoprostheses are being extensively studied in some clinics [9, 15-18]. The number of experimental works on the problem is very few $[9,17]$. The effect of mesh material on the structure and size of a postoperative scar remains a matter of argument. In order to increase biological and biomechanical compatibility of implants there have been studied the capabilities of various titanium-containing mesh prostheses, where titanium and its compounds either form implant structure, or coat the endoprosthesis surface coming in contact with the body tissues [19-22]. The peculiarities of possible differences of connective tissue developing in the implantation area of synthetic and titanium-containing endoprostheses are unresearched so far.

The aim of the investigation was to study in experiment strength properties of connective tissue formation in the area of synthetic and titanium-containing endoprostheses implanted during abdominal wall prosthetic repair.

Materials and Methods. Abdominal wall prosthetic repair was modeled on the basis of M.M. Shemyakin and Yu.A. Ovchinnikov Institute of Bioorganic Chemistry, Russian Academy of Sciences and Moscow State Design and Technology University. The study was performed by authority of the Ethics Committee of Central Clinical Hospital of the Russian Academy of Sciences in accordance with Russian Federation legislation ("Humane treatment of laboratory animals", "Deontology of a biomedical experiment") and the ethics principles established by European Convention for the Protection of Vertebrate Animals used for Experimental and other Scientific Purposes (adopted in 18.03.1986 in Strasburg and approved in 15.06.2006 in Strasburg). The design and methodology of the experiment were in complete agreement with the main principles of $3 R$ concept (reduction, refinement, replacement), which is currently used in experimental surgery and biology [23].

The operation was performed on mature rabbits $(n=54)$ under general anesthesia by combination of Rometar (2 $\mathrm{mg} / \mathrm{kg})$ and Zoletil $(8 \mathrm{mg} / \mathrm{kg}$ ) intramuscularly. Animal weight by the surgery time was $3,524 \pm 366 \mathrm{~g}$. Group 1 animals were implanted synthetic endoprostheses of polypropylene (PP Light, fiber $90 \mu \mathrm{m}$, surface density: $36 \mathrm{~g} / \mathrm{m}^{2}$, distributed volume index: $\left.39.6 \mathrm{~cm}^{3} / \mathrm{m}^{2}\right)$; group 2 animals had titanium-containing implants made from polypropylene (TiMesh, fiber $65 \mu \mathrm{m}$, surface density: $16 \mathrm{~g} / \mathrm{m}^{2}$, distributed volume index: $17.58 \mathrm{~cm}^{3} / \mathrm{m}^{2}$ ) with titanium coating applied by PACVD (plasma-activated chemical vapor deposition) technology; group 3 animals had meshes made from titanium threads ("Titanium silk", fiber $65 \mu \mathrm{m}$, surface density: $45 \mathrm{~g} / \mathrm{m}^{2}$, distributed volume index: $10.41 \mathrm{~cm}^{3} / \mathrm{m}^{2}$ ). All the mentioned endoprostheses refer to woven ones according to Zhukovsky classification [24], and can be consider as categories 1a and 1c according to Klinge-Klosterhalfen classification [7]. As consistent with Coda ideas [8], the specified implants should be taken as lightweight and ultra-lightweight. Anurov [9] refer the implants with such characteristics to ultra-lightweight ones.

The principles of prosthetic repair performing were 
consistent with the approaches recognized in modern herniology, being in agreement with the regulations authorized by the conferences of Russian Society of Herniology, and were no different from those described in classical guidelines and original articles on the issue $[3,25,26]$. We observed conventional in experimental surgery sizes of endoprostheses $(3 \times 3 \mathrm{~cm})$ the rabbits were implanted. The meshes were fixed typically using atraumatic sutures of polypropylene thread $4 / 0$. The mentioned aspects enable to compare correctly the experimental findings with those having obtained before by Russian and foreign researchers.

To study strength characteristics of connective tissue forming around an endoprosthesis we used the model involving two similar meshes implanted close to each other.

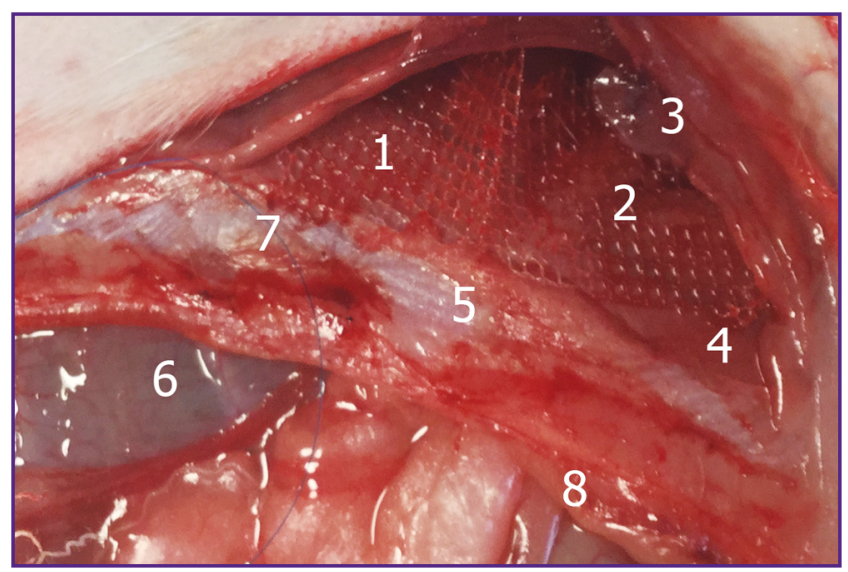

Figure 1. Retromuscular implantation of TiMesh: the first endoprosthesis (1); the second endoprosthesis (2); rectus abdominis muscle (3); posterior leaf of sheath of rectus abdominis muscle (4); white line (5); small intestine (6); ligature (7); peritoneum (8)

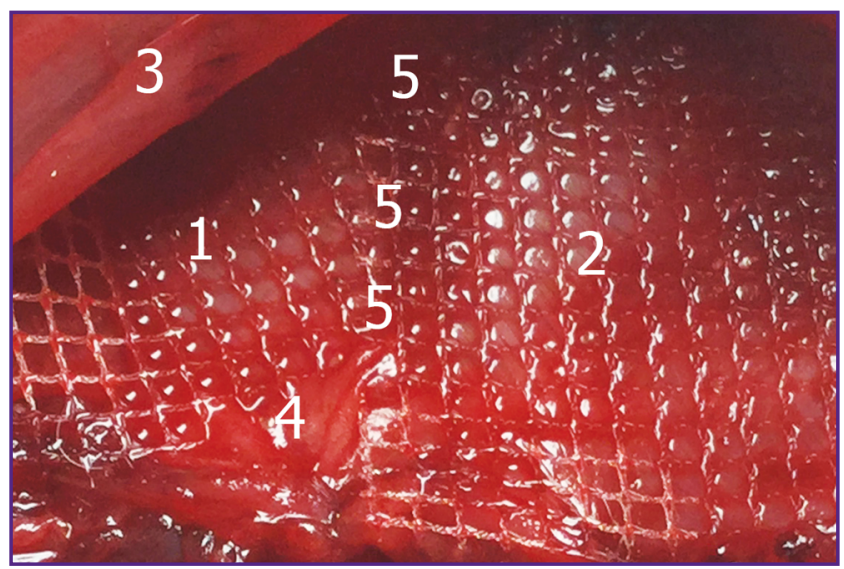

Figure 3. Retromuscular implantation of TiMesh: the first endoprosthesis (1); the second endoprosthesis (2); rectus abdominis muscle (3); posterior leaf of sheath of rectus abdominis muscle (4); contact area of endoprostheses (5)
In the first experimental series the surgical technique complied with the main principles of SRM (sublay retromuscular) technique, which is identical to retromuscular repair of abdominal wall (according to Timoshin) [25]. Midline laparotomy was performed. The sheaths of rectus abdominis muscles were opened, and retromuscular space was dissected. The abdominal cavity and posterior leaves of rectus abdominis muscles were sutured. On the posterior leaves, behind the abdominal rectus muscles we placed two endoprostheses of the same type, $3 \times 3 \mathrm{~cm}$ in size, by fixing them to the posterior leaves of rectus abdominis muscles along the perimeter by atraumatic suture of polypropylene thread 4/0. Figures 1-4 show the implantation stages. The mentioned meshes were placed in such a way that they would come in touch

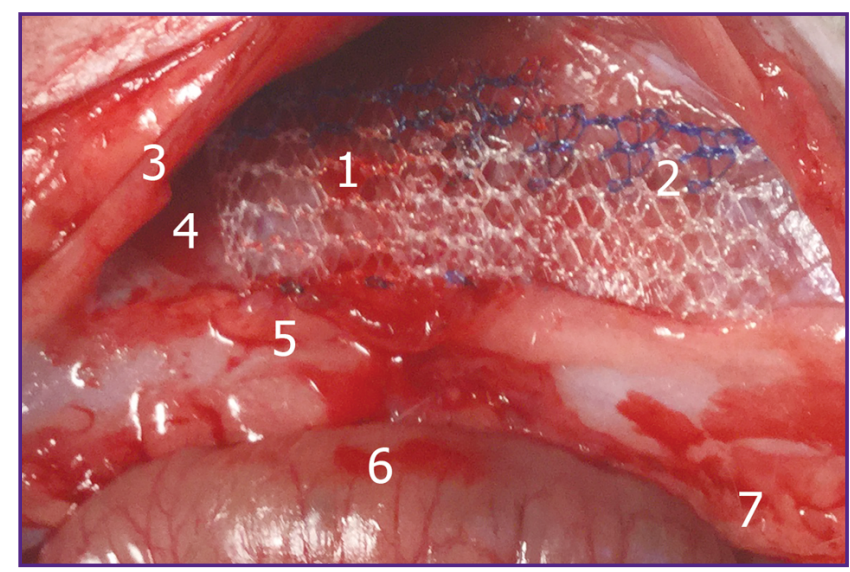

Figure 2. Retromuscular implantation of PP Light meshes: the first endoprosthesis (1); the second endoprosthesis (2); rectus abdominis muscle (3); posterior leaf of sheath of rectus abdominis muscle (4); white line (5); small intestine (6); peritoneum (7)

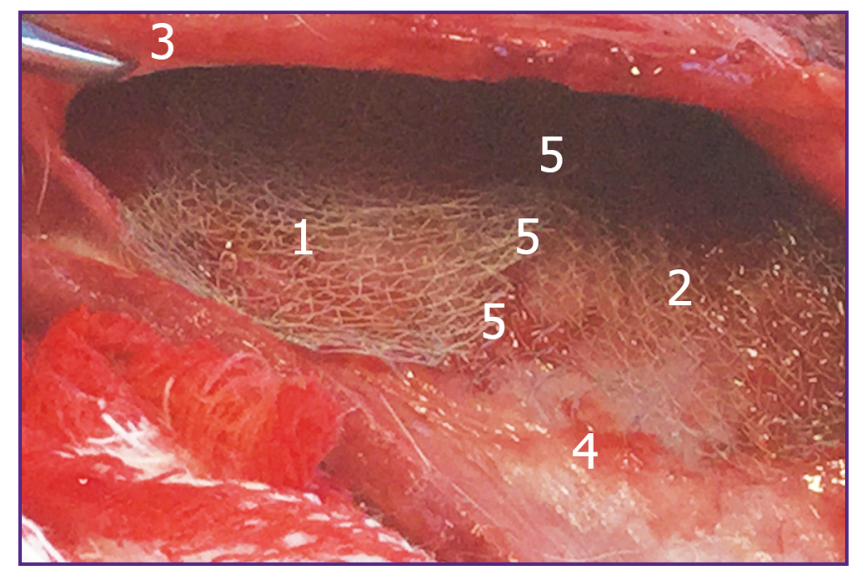

Figure 4. Retromuscular implantation of meshes of titanium threads Titan: the first endoprosthesis (1); the second endoprosthesis (2); rectus abdominis muscle (3); posterior leaf of sheath of rectus abdominis muscle (4); contact area of endoprostheses (5) 
by their edges (See Figures 3, 4). Then we sutured the anterior leaves of the sheaths of rectus abdominis muscles and the wound.

The second experimental series of the operative technique was consistent with the main principles of IPOM (intraperitoneal onlay mesh). Midline laparotomy was performed. Two endoprostheses, $3 \times 3 \mathrm{~cm}$ in size, were placed intraperitoneally, and fixed to the parietal peritoneum along the perimeter by atraumatic suture of polypropylene thread 4/0. Figures 5-7 show the implantation stages. As in the first series, we placed the meshes in such a way that they would come in touch by their edges (See Figures 6, 7). Then we sutured the abdominal wall and the wound.

Table 1 demonstrates the distribution of implantations. Generation I cephalosporin was administered perioperatively at standard doses as antibiotic prophylaxis. During the postoperative period the animals had free access to food and water. The animals were

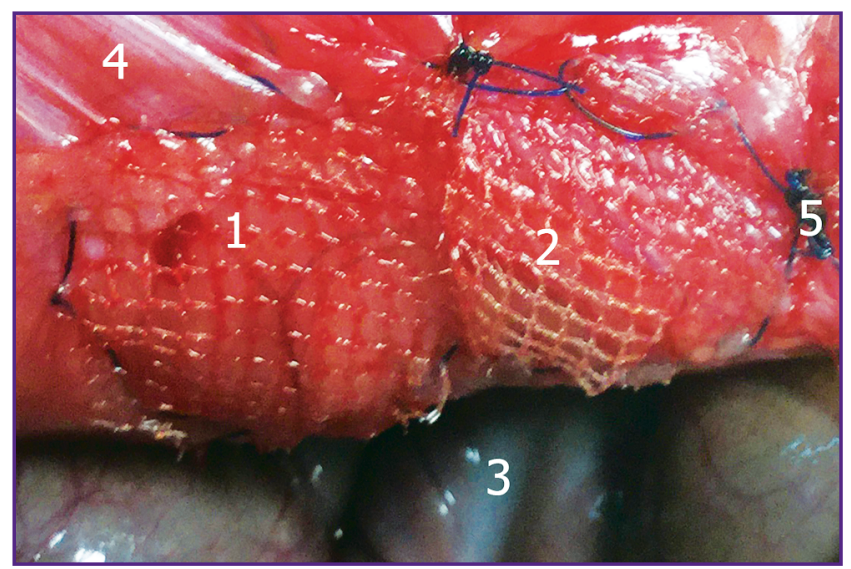

Figure 5. Intraperitoneal implantation of TiMesh meshes: the first endoprosthesis (1); the second endoprosthesis (2); intestine (3); peritoneum (4); ligature (5)

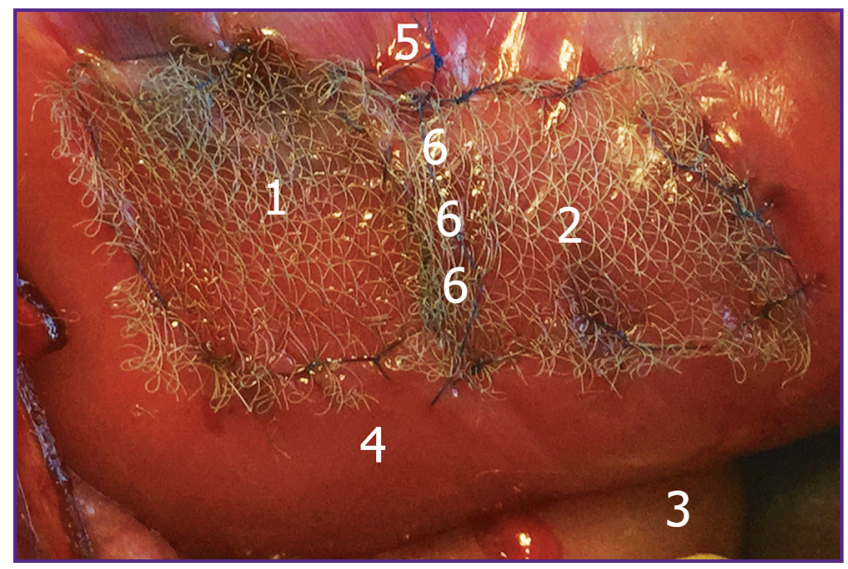

Figure 6. Intraperitoneal implantation of Titan meshes: the first endoprosthesis (1); the second endoprosthesis (2); intestine (3); peritoneum (4); ligature (5); contact area of endoprostheses (6)

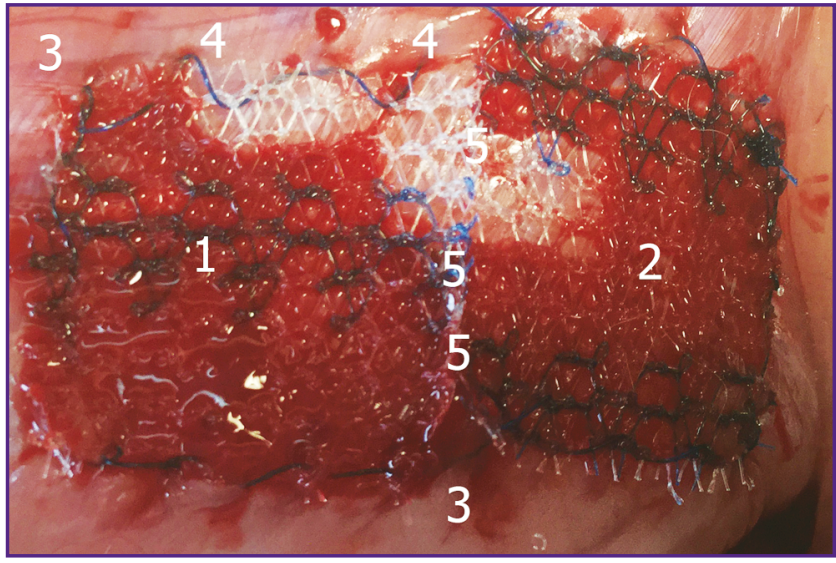

Figure 7. Intraperitoneal implantation of PP Light meshes: the first endoprosthesis (1); the second endoprosthesis (2); peritoneum (3); ligature (4); contact area of endoprostheses (5)

Table 1

Implantation distribution in groups

\begin{tabular}{lcccc}
\hline \multicolumn{1}{c}{ Series } & \multicolumn{3}{c}{ Group } & Total \\
\cline { 2 - 3 } IPOM & 1 & 2 & 3 & \\
\hline SRM & 9 & 9 & 9 & 27 \\
Total & 9 & 9 & 9 & 27 \\
\hline
\end{tabular}

H e r e. IPOM series: intraperitoneal plasty; SRM series: retromuscular plasty; group 1: lightweight synthetic polypropylene mesh; group 2: titanium-coated ultralightweight mesh; group 3: mesh of titanium threads.

anesthetized by administering non-opioid analgesics at recommended doses. The animals were followed up for a month, examined, weighed, and sacrificed on day 30 and 60 by air embolism $(7 \mathrm{ml} / \mathrm{kg})$ under general anesthesia by Rometar $(2 \mathrm{mg} / \mathrm{kg})$ and Zoletil $(8 \mathrm{mg} / \mathrm{kg})$ intramuscularly.

Then we exected abdominal wall strips with endoprostheses, $10 \mathrm{~cm}$ long and $1 \mathrm{~cm}$ wide. The strips were placed in a tensile strength testing machine Instron 5560 (Instrom Limited, Great Britain), a conventional index being obtained in $\mathrm{N} / \mathrm{cm}$. We used the technique similar to that described by Parfenov and Zhukovsky [17], though modified. For this purpose one clump of the apparatus grasped the first mesh, and another clump the second mesh so that tissue complex could tear at the contact area of the meshes. The approach rules out the effect of strength characteristics of the mesh itself on tensile strength of connective tissue formed along the endoprosthesis perimeter. So, during the survey it was strength characteristics of the newly formed abdominal wall we studied, the area under study being located between the endoprostheses implanted. It was a distinguishing feature of the study compared to other 
known models, where, as a matter of fact, we studied tensile strength and strength of a complex "abdominal wall tissue + mesh" $[9,17]$.

Value distribution was studied by Shapiro-Wilk test and Lilliefors test. Nonparametric sequences were analyzed using Kolmogorov-Smirnov test by means of Origin Pro 8 in Windows 8 on a computer Dell Inspiron Core i7. The differences were considered significant if $p<0.05$.

Results. No lethal complications were found in any groups. By day 30 of the experiment animal weight was $3,424 \pm 292 \mathrm{~g}$, i.e. significantly lower than the initial weight; and by day 60 it grew up to $3,840 \pm 536 \mathrm{~g}$ that was significantly higher compared to the initial data (Table 2). The characteristics of the newly formed connective tissue in the implanted mesh area were found to depend on the properties of an endoprosthesis used (synthetic or titatiumcontaining), repair technique and research duration (Figure 8).

Connective tissue strength in group 2 (titanium-containing mesh of polypropylene fibers with titanium coating) was higher $(13.12 \mathrm{~N} / \mathrm{cm}$ ) than in group 1 (synthetic endoprosthesis of lightweight polypropylene: $9.2 \mathrm{~N} / \mathrm{cm}$ ) in both research series; $p=0.001$. In group 3 (a mesh of titanium threads) the mentioned parameter was maximal $(15.89 \mathrm{~N} / \mathrm{cm})$ that differs significantly from the findings in group $1(p=0.0000)$ and $2(p=0.002)$ (Table 3). However, we observed no coarse scars in the implantation area of titanium meshes (Figure 9). The comparison of two series showed connective tissue strength after SRM to be higher $(13.32 \mathrm{~N} / \mathrm{cm})$ than that after IPOM (12.88 N/cm); $p=0.976$ (Table 4). The parameter under study was significantly higher on day 60 of the experiment $(13.9 \mathrm{~N} / \mathrm{cm})$ compared to the findings of day 30 after the surgery $(12.4 \mathrm{~N} / \mathrm{cm}) ; p=0.008$ (Table 5$)$. What stands out in the study is that abdominal wall strength along the implantation perimeter was significantly lower $(12.4 \mathrm{~N} / \mathrm{cm})$ on day 30 compared to that in intact zones $(14.84 \mathrm{~N} / \mathrm{cm})$; $p=0.0004$. By day 60 of the postoperative period there were no significant differences in strength between the study areas and intact zones; $p=0.08$ (See Table 5).

Thus, an implantation technique and endoprosthesis composition have an effect on the strength of connective tissue formed in the repair area. The parameter undergoes no changes during the postoperative period, and by day 60 has no essential differences compared

Table 2

Animal weight at experimental stages

\begin{tabular}{|c|c|c|c|c|c|c|c|c|c|}
\hline \multirow{2}{*}{$\begin{array}{l}\text { Measurement } \\
\text { time }\end{array}$} & \multicolumn{7}{|c|}{ Weight (g) } & \multirow{2}{*}{\multicolumn{2}{|c|}{$p$}} \\
\hline & Min & Q1 & Median & Mean & $S D$ & Q3 & Max & & \\
\hline Initial & 2,950 & 3,240 & 3,545 & 3,524 & 366 & 3,790 & 4,150 & \multirow{3}{*}{0.046} & \multirow{3}{*}{0.001} \\
\hline Day 30 & 2,820 & 3,300 & 3,510 & 3,424 & 292 & 3,620 & 3,770 & & \\
\hline Day 60 & 2,900 & 3,520 & 3,740 & 3,840 & 536 & 4,200 & 4,800 & & \\
\hline
\end{tabular}

He r e. Min: minimal value; Q1: first quartile; Me: median; Mean: arithmetic mean; SD: standard deviation; Q3: third quartile; Max: maximal value; p: test of significance; ]: amount of data compared.

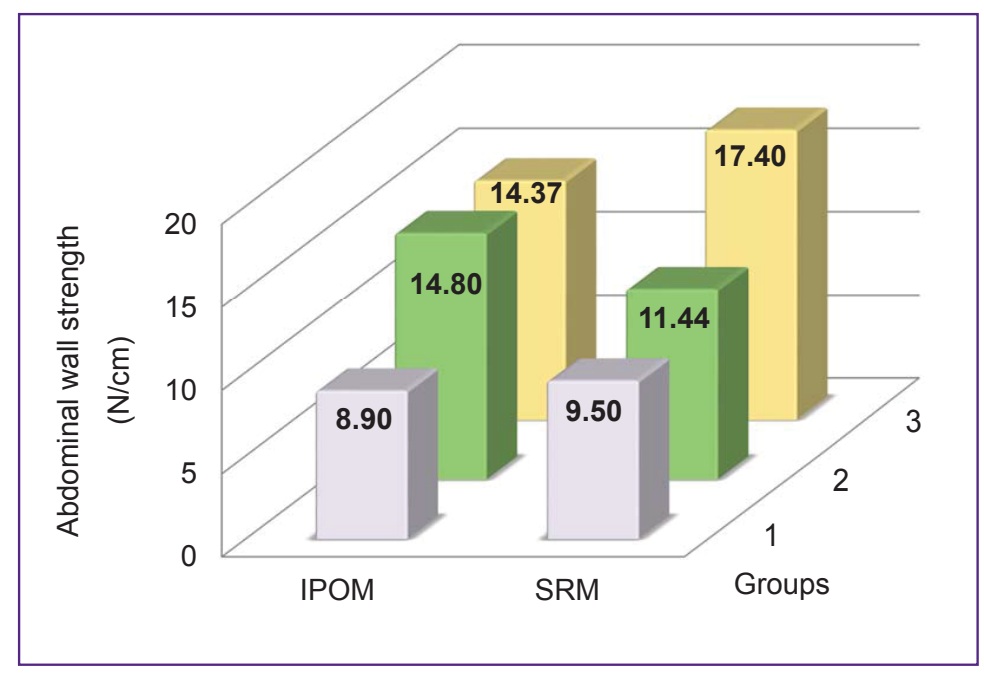

Figure 8. Abdominal wall strength along the perimeter of mesh implantation. Series: IPOM (intraperitoneal plasty), SRM (retromuscular repair); groups: lightweight polypropylene mesh (1); ultra-lightweight polypropylene mesh, titanium-coated (2); a mesh of titanium threads (3)

Table 3

Connective tissue strength in the study group

\begin{tabular}{|c|c|c|c|c|c|c|c|c|c|c|}
\hline \multirow{2}{*}{ Group } & \multicolumn{7}{|c|}{ Strength $(\mathrm{N} / \mathrm{cm})$} & \multirow{2}{*}{\multicolumn{3}{|c|}{$p$}} \\
\hline & Min & Q1 & Median & Mean & $S D$ & Q3 & Max & & & \\
\hline 1 & 6.1 & 6.8 & 9.05 & 9.2 & 2.5 & 10.8 & 14.3 & \multirow{3}{*}{0.001} & \multirow[b]{3}{*}{0.02} & \multirow{3}{*}{0.000003} \\
\hline 2 & 8.6 & 10.7 & 13.55 & 13.12 & 3.34 & 14.2 & 20.8 & & & \\
\hline 3 & 7.7 & 14.1 & 15.6 & 15.89 & 4.65 & 20.4 & 23.2 & & & \\
\hline
\end{tabular}

H e r e. Min: minimal value; Q1: first quartile; Me: median; Mean: arithmetic mean; SD: standard deviation; Q3: third quartile; Max: maximal value; $p$ : test of significance; ]: amount of data compared. 


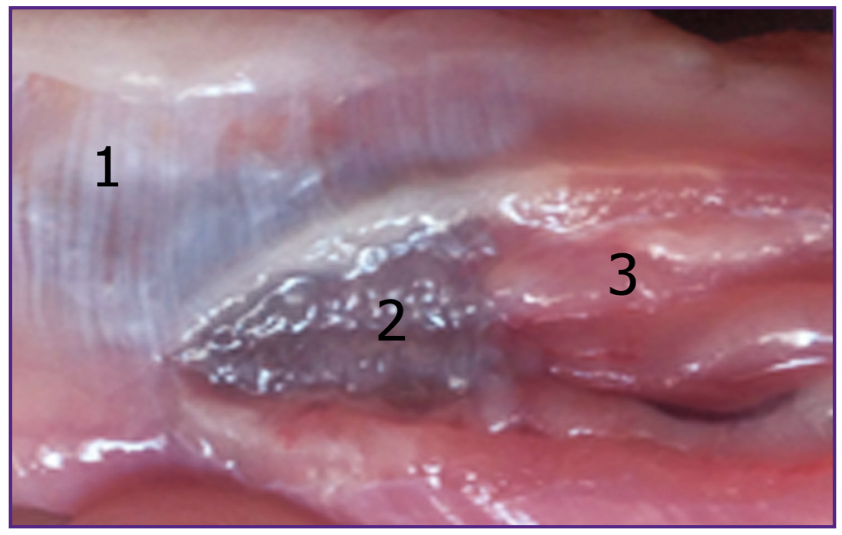

Figure 9. The view of titaniumcontaining mesh implantation. There is no coarse scar tissue in the repair area: peritoneum (1); mesh (2); abdominal wall muscles (3)

Table 4

Comparative analysis of experimental series

\begin{tabular}{|c|c|c|c|c|c|c|c|c|}
\hline \multirow{2}{*}{ Series } & \multicolumn{7}{|c|}{ Strength $(\mathrm{N} / \mathrm{cm})$} & \multirow{2}{*}{$p$} \\
\hline & Min & Q1 & Median & Mean & $S D$ & Q3 & Max & \\
\hline IPOM & 6.8 & 9.35 & 13.0 & 12.88 & 4.15 & 14.76 & 21.7 & \multirow{2}{*}{0.976} \\
\hline SRM & 6.1 & 8.83 & 14.1 & 13.32 & 5.11 & 16.5 & 23.2 & \\
\hline
\end{tabular}

H e r e. Min: minimal value; Q1: first quartile; Me: median; Mean: arithmetic mean; SD: standard deviation; Q3: third quartile; Max: maximal value; p: test of significance.

Table 5

\section{Comparative analysis of experimental stages}

\begin{tabular}{|c|c|c|c|c|c|c|c|c|c|c|}
\hline \multirow{2}{*}{ Investigation period } & \multicolumn{7}{|c|}{ Strength $(\mathrm{N} / \mathrm{cm})$} & \multirow{2}{*}{\multicolumn{3}{|c|}{$p$}} \\
\hline & Min & Q1 & Median & Mean & SD & Q3 & Max & & & \\
\hline Day 30 after surgery & 6.1 & 8.3 & 10.95 & 12.4 & 5.58 & 14.3 & 23.2 & \multirow{3}{*}{0.008} & \multirow{3}{*}{0.0004} & \\
\hline Day 60 after surgery & 8.9 & 11.05 & 14.35 & 13.9 & 3.15 & 15.75 & 20.4 & & & \multirow{2}{*}{0.08} \\
\hline Intact abdominal wall & 11 & 13.93 & 14.9 & 14.84 & 1.89 & 16.05 & 17.8 & & & \\
\hline
\end{tabular}

H e r e. Min: minimal value; Q1: first quartile; Me: median; Mean: arithmetic mean; SD: standard deviation; Q3: third quartile; Max: maximal value; p: test of significance; ]: amount of data compared.

to that of the intact abdominal wall. The peculiarities found should be taken into consideration when planning operations for ventral and incisional hernias to reduce the incidence of recurrent disease.

Discussion. The results of the experiment showed the strength of newly formed connective tissue in the endoprosthesis implantation area to be sufficient enough. The reduction in mesh surface density does not decrease the parameter. Moreover, it appeared to be higher in group 2 compared to group 1; group 3 animals were found to have the maximum index. In the course of the experiment we found the application of titaniumcontaining meshes to be associated with the formation of stronger connective tissue than in cases with synthetic meshes. It is entirely possible that it is due to a positive effect of titanium covering polypropylene fibers or as a single material for mesh fabrication. The fact is consistent with other experimental studies [27].
The results of our study are in agreement with accumulated clinical findings. In foreign literature there is a report on positive experience of using lightweight and ultra-lightweight titanium-containing polypropylene meshes [28]. Russian researchers have reported on successful application of mesh implants made from titanium threads in abdominal wall repair [19, 20, 29]. Titanium is well known to have a positive effect on reparative process and local immunity factors that has been convincingly demonstrated in some fundamental researches [21, 22].

The findings of the present study are in agreement with the data of the authors, who studied the strength of intact and operated abdominal wall on similar laboratory animals. The values of the parameter the authors received are comparable with reference intervals found when carrying out such investigations [9], however, still there are differences due to the peculiarities of 
experimental models used by different authors. It should be noted that the authors of the present study used the abdominal wall along the white line.

The strength of newly formed abdominal wall appeared to be significantly lower than similar parameters of an endoprosthesis itself. Anurov [9] brings such index for PP Light being $28.6 \pm 1.6 \mathrm{~N} / \mathrm{cm}$ (lengthwise) or $36.9 \pm 3.3 \mathrm{~N} / \mathrm{cm}$ (crosswise).

Parfenov [17] has published different data: 18.6 and $46.2 \mathrm{~N} / \mathrm{cm}$, respectively. The author indicates that after connective tissue capsule formation, as a natural result, "endoprosthesis-capsule" complex strength becomes higher than the initial value, and by day 30 it is $24.60 \pm 2.24$ and $53.20 \pm 1.13 \mathrm{~N} / \mathrm{cm}$. In the present research endoprostheses were implanted according to onlay technique only. Moreover, we studied connective tissue capsule strength, the strength being assessed indirectly (together with a mesh).

The present study has analyzed the results of SRM and IPOM techniques using lightweight and ultralightweight meshes. It is important to note that in our study strength property was determined, actually, for the operated (newly formed) abdominal wall, and not for a mesh or a connective tissue capsule alone. It is of great importance for hernia recurrence prognosis and prevention. The mentioned works of our colleagues studied strength and extensibility of connective tissue together with a mesh that is very important to prognosticate functional results of operations but not determine hernia recurrence risk.

It should be emphasized that we do not think that strength or extensibility of a newly formed abdominal wall are just the only characteristics determining clinical results. The properties of an endoprosthesis are certain to have a significant effect on strength characteristics of the operated abdominal wall. However, even experimentally the effect is ambiguous in different series. A technique is of certain value; therefore, mesh selection should be appropriate for the operations a surgeon is familiar with.

An adequate abdominal wall reconstruction should be considered the fundamental condition of hernia recurrence prevention. Currently, most authors assume such attitude [3]. In this view, the application of lightweight and ultra-lightweight materials in some situations is possible and efficient. The approach under consideration is more close to that suggested by Egiev et al. [10], but differs significantly from the recommendations by Anurov [9]. The last work shows only standard, medium or heavy endoprostheses to be used for onlay and sublay techniques, while lightweight meshes are acceptable in small inguinal hernias, and the implantation of ultra-lightweight materials is not recommended.

Conclusion. Experimentally, the use of lightweight and ultra-lightweight synthetic and titaniumcontaining endoprostheses for abdominal wall repair is accompanied by connective tissue formation of sufficient strength. The indicated parameter in the implantation of titanium-coated ultra-lightweight polypropylene mesh is higher than that in lightweight polypropylene mesh, the strength of a mesh of titanium threads being maximum. Along the implantation area perimeter an abdominal wall has satisfactory indices of tensile strength comparable with the strength of an intact abdominal wall, and by day 60 after surgery the indices were no different from the latter. In clinical settings lightweight and ultra-lightweight can be safely used if abdominal wall repair is adequately performed. The application of titanium-containing endoprostheses in abdominal wall repair is accompanied by the formation of stronger connective tissue than in synthetic endoprostheses.

Study Funding. The study was supported by Ministry of Education and Science, unique identifier of the project is RFMEFI60714X0085.

Conflicts of Interest. The authors have no conflicts of interest related to the present study.

\section{References}

1. Aver'yanov M.Yu., Mukhin A.S. Khirurgiya abdominal'nykh gryzh [Abdominal hernial surgery]. Kirov; 2014; $407 \mathrm{p}$.

2. Kukosh M.V., Vlasov A.V., Gomozov G.I. Prevention of early incisional complications in ventral hernia prosthetic repair. Novosti khirurgii 2012; 5: 32-37.

3. Iurasov A.V., Shestakov A.L., Kurashvili D.N., Abovian L.A. The modern concept of surgical treatment of patients with postoperative hernias of the anterior abdominal wall. Vestnik eksperimental'noy i klinicheskoy khirurgii 2014; 4: 405-413.

4. Tsverov I.A., Bazaev A.V. Surgical treatment of patients with ventral hernias: modern state. Sovremennye tehnologii $v$ medicine 2010; 4: 122-127.

5. Romanov R.V., Fedaev A.A., Petrov V.V., Khodak V.A., Parshikov V.V. The intraperitoneal tension-free plasty of abdominal wall with mesh use - current state of problem. Sovremennye tehnologii v medicine 2012; 4: 161-170.

6. Brown C.N., Finch J.G. Which mesh for hernia repair? Ann R Coll Surg Engl 2010; 92(4): 272-278, http://dx.doi.org/ 10.1308/003588410X12664192076296.

7. Klinge U., Klosterhalfen B. Modified classification of surgical meshes for hernia repair based on the analyses of 1,000 explanted meshes. Hernia 2012; 16(3): 251-258, http:// dx.doi.org/10.1007/s10029-012-0913-6.

8. Coda A., Lamberti R., Martorana S. Classification of prosthetics used in hernia repair based on weight and biomaterial. Hernia 2012; 16(1): 9-20, http://dx.doi. org/10.1007/s10029-011-0868-z.

9. Anurov M.V. Vliyanie strukturnykh i mekhanicheskikh svoystv setchatykh protezov na effektivnost' plastiki gryzhevykh defektov bryushnoy stenki. Dis. ... dokt. med. nauk [The effect of structural and mechanical properties of mesh prostheses on abdominal wall hernia defect plasty efficacy. DSc Thesis]. Moscow; 2014.

10. Egiev V.N., Shurygin S.N., Chizhov D.V. The 
comparison of abdominal wall plasty with "heavy" and "light" polypropylene endoprostheses in the treatment of incisional ventral hernias. Moskovskiy khirurgicheskiy zhurnal 2012; 2: 20-23.

11. Li J., Ji Z., Zhang W., Li L. The comparison of lightweight mesh and standard mesh in incisional hernia repair with the open sublay technique: the results of a meta-analysis. Surg Laparosc Endosc Percutan Tech 2015; 25(3): 238-244, http://dx.doi.org/10.1097/SLE.0000000000000144.

12. Ladurner R., Chiapponi C., Linhuber Q., Mussack T. Long term outcome and quality of life after open incisional hernia repair - light versus heavy weight meshes. BMC Surg 2011; 11: 25, http://dx.doi.org/10.1186/1471-2482-11-25.

13. Cobb W.S., Warren J.A., Ewing J.A., Burnikel A., Merchant M., Carbonell A.M. Open retromuscular mesh repair of complex incisional hernia: predictors of wound events and recurrence. J Am Coll Surg 2015; 220(4): 606-613, http:// dx.doi.org/10.1016/j.jamcollsurg.2014.12.055.

14. Upyrev A.V., Khmel'nitskiy A.I., Volokitin A.S., Surov N.D., Eliseeva G.A., Romanov V.A., Mel'nikov G.A. Retsidiv posleoperatsionnoy ventral'noy gryzhi: sroki formirovaniya pri plastike bryushnoy stenki sovremennymi setochnymi implantatami i mestnymi tkanyami. V kn.: Materialy $X$ nauchnoy konferentsii "Aktual'nye voprosy gerniologii" [Incisional ventral hernia recurrence: development time in abdominal wall plasty using modern mesh implants and patient's tissues. In: Proceedings of $X$ conference "Urgent problems of herniology"]. Moscow; 2012; p. 156-157.

15. Belokonev V.I., Fedorina T.A., Pushkin S.Yu., Nagapetyan S.V. Morphological substantiation of biomechanical concept of ventral hernia pathogenesis. Morfologicheskie vedomosti 2009; 3(part 4): 121-124.

16. Andryushchenko V.P., Kushnirchuk N.I. Micro- and ultrastructural changes of the anterior abdominal wall tissues as a principle of selection of a hernioplasty technique in incisional ventral hernias. Astrakhanskiy meditsinskiy zhurnal 2012; 4: 18-21.

17. Parfenov A.O. Sravnitel'naya otsenka roli razlichnykh endoprotezov dlya gernioplastiki $v$ razvitii morfologicheskikh izmeneniy bryushnoy stenki. Dis. ... kand. med. nauk [Comparative assessment of various endoprostheses for hernia repair in the development of abdominal wall morphological changes. DSc Thesis]. Kursk; 2014.

18. Khokhlov K.S., Bondarev O.I., Gorokhova L.G., Bugaeva M.S., Voenkova D.V. Pathomorphological research of non-pull reconstructive surgery in experimental treatment of postoperative ventral hernia. Fundamental'nye issledovaniya 2011; 11(2): 372-376.

19. Parshikov V.V., Samsonov A.V., Romanov R.V., Gradusov V.P., Khodak V.A., Petrov V.V., Tsybusov S.N., Baburin A.B., Kihlyarov P.V., Kazantsev A.A. The first experience of tension-free abdominal wall repair with titan mesh. Meditsinskiy al'manakh 2011; 1(20): 107-110.

20. Limonov A.V., Titov D.A., Zabrodin V.V., Valiyev E.F., Zabrodin Ye.V. Application of titanium mesh endoprosthesis for allotransplantation of inguinal hernias. Meditsinskiy vestnik MVD 2014; 1(68): 49-51.

21. Sarbayeva N.N., Ponomareva J.V., Volova L.T. Activation of rat peritoneal macrophages on the surface of the endoprothesis used for hernia repair. Tekhnologii zhivykh sistem 2013; 8: 84-89.

22. Chernov A.V., Irianov Yu.M., Radchenko S.A., Chernov V.F., Irianova T.Yu. Studying the integration features of different biomaterials in organism soft and bone tissues. Geniy ortopedii 2012; 1: 97-101.

23. Karkischenko N.N. Bioetika v eksperimental'nykh issledovaniyakh. V kn.: Osnovy biomodelirovaniya [Bioethics in experimental studies. In: The basics of biomodelling]. Moscow; 2005; p. 291-314.

24. Zhukovsky V.A. Polimernye endoprotezy dlya gernioplastiki [Polymer implants for hernia repair]. Saint Petersburg: Eskulap; 2011.

25. Timoshin A.D., Iurasov A.V., Shestakov A.L. Conference "Actual problems of herniology". Khirurgiya. Zhurnal im. N.I. Pirogova 2007; 7: 80.

26. Pushkin S.Yu., Belokonev V.I. Treatment of medial ventral hernias with the use of synthetic endoprosthesis. Khirurgiia. Zhurnal im. N.I. Pirogova 2010; 6: 43-45.

27. Pereira-Lucena C.G., Artigiani Neto R., de Rezende D.T., Lopes-Filho-Gde J., Matos D., Linhares M.M. Early and late postoperative inflammatory and collagen deposition responses in three different meshes: an experimental study in rats. Hernia 2014; 18(4): 563-570, http:// dx.doi.org/10.1007/s10029-013-1206-4.

28. Köckerling F., Schug-Pass C. What do we know about titanized polypropylene meshes? An evidence-based review of the literature. Hernia 2014; 18(4): 445-457, http://dx.doi. org/10.1007/s10029-013-1187-3.

29. Kolpakov A.A., Kazantsev A.A. Comparative analysis of the results of titanium and polypropylene prostheses in patients with incisional ventral hernias. Russkiy meditsinskiy zhurnal 2015; 13: 774-775. 